\title{
Efeitos do Programa Educacional de Resistência às Drogas e à Violência (PROERD) entre estudantes do Ensino Fundamental no Cariri cearense: Um estudo Comparativo
}

\author{
José Demontier Guedes ${ }^{1}$; Alex Figueirêdo da Nóbrega ${ }^{2}$
}

\begin{abstract}
Resumo: No presente estudo buscou-se discutir os efeitos do Programa Educacional de Resistência às Drogas e à Violência (PROERD) na prevenção ao uso de drogas em relação aos fatores de proteção e redução da vulnerabilidade, abordando também os aspectos de relacionamento e convívio familiar. O Programa atua especificamente na prevenção primária, discutindo os malefícios que as drogas podem causar e as técnicas para manter-se afastado e resistir às ofertas. A pesquisa teve como objetivo caracterizar o Programa e seus efeitos, partindo da escuta de estudantes atendidos por este em relação a sua participação no curso e também daqueles que não tiveram a oportunidade de participar das instruções. Desse modo, resulta-se na identificação da postura dos alunos em relação à resistência ao uso de drogas. Objetivou-se ainda, identificar a percepção dos educandos quanto à resistência ao uso de drogas. A construção deste trabalho possibilitou uma melhor compreensão das ações do Proerd, tanto nas relações familiares quanto educacionais, ao tempo em que retrata questões de aceitação de substâncias químicas e faz um comparativo do uso entre os concludentes do curso com aqueles que não participaram. $\mathrm{O}$ método da pesquisa foi quantitativo com levantamento de dados através de questionário elaborado pelo próprio pesquisador. A amostra da pesquisa foi de 392 alunos, divididos entre seis municípios da Região do Cariri Cearense, nas séries do $6^{\circ}$ ao $9^{\circ}$ anos. Destes 229 participaram do Proerd e 163 não tiveram as instruções de prevenção. Analisando os resultados obtidos na pesquisa, percebeu-se que, houve diferença estatisticamente significativa em relação ao consumo de cigarro e álcool entre os estudantes participantes e não do Programa, bem como a taxa de consumo conforme avaliação da escola onde estuda, da frequência e da participação dos pais na vida escolar.
\end{abstract}

Palavras-chave: Drogas. Prevenção. Proerd.

\section{The effects of Educational Program of Resistance to Drugs and Violence (PROERD) Among Students of Education of Fundamental Cearense Cariri Region: A Comparative Study}

\begin{abstract}
In this study we aimed to discuss the effects of Educational Program of Resistance to Drugs and Violence (PROERD) in preventing drug use in relation to protective factors and reducing vulnerability, also addressing aspects of relationships and family life. The program acts specifically on primary prevention, discussing the harms that drugs can cause and techniques tokeep away and resist offers. Thus, it results in the identification of the attitude of students for resistance to drug use. The objective was to further identify the perception of students as resistance to drug use. The construction of this work enabled a better understanding of Proerd actions, both familiar and educational relationships, the time that portrays acceptance issues of chemicals and makes a comparison of the use of the course conclusive with those who did not. The research method was quantitative with data collecting through questionnaire prepared by the researcher. The survey sample was 392 students, divided into six municipalities of the Cariri Cearense Region, in the series of 6 to $9^{\circ}$ anos. Of these 229 participated in the Proerd and 163 did not have the instructions prevention. Analyzing the results obtained in the survey, it was realized that there was statistically significant in relation to the consumption of tobacco and alcohol among participants and not the program students as well as the consumption rate as assessed school where he studied, the frequency and participation parents in school life.
\end{abstract}

Keywords: Drugs. Prevention. Proerd.

\footnotetext{
${ }^{1}$ Mestre em Ciências da Educação. Psicólogo. Pedagogo. Especialista em Português e arte/educação. Mentor/Educador Social na prevenção ao uso de drogas e violência em escolas públicas e privadas na Região do Cariri Cearense através do Programa Educacional de Resistência às Drogas e à Violência - PROERD;

${ }^{2}$ Psicólogo pela Universidade Federal da Paraíba (2001-2006) e especialização em Saúde da Família pela Universidade Gama-Filho. Mestrando em Desenvolvimento Regional Sustentável da Universidade Federal do Cariri (PRODER/UFCA).
} 


\section{Introdução}

O discurso sobre a prevenção do uso de drogas tem estimulado o debate em diversos segmentos da sociedade, especialmente nas instituições de ensino, palco de uma diversidade de indivíduos, os quais passam a receber informações para o exercício da cidadania e valorização da vida. Nesse contexto, o Programa Educacional de Resistência às Drogas e à Violência (PROERD) se destaca pela atuação no ambiente escolar, estando semanalmente presente nas atividades educacionais dos alunos.

O Proerd atua especificamente na prevenção do uso de drogas em escolas públicas e particulares de ensino fundamental. O objetivo principal do programa é instruir estudantes das instituições de ensino para resistir às ofertas de drogas, com ênfase na prevenção primária.

Diante disso, o tema em destaque foi escolhido para realizar um estudo sobre a atuação do Programa na capacitação de alunos através de informações sobre os efeitos das drogas, buscando alertar quanto aos riscos que estas podem causar aos usuários. Buscou-se também, divulgar as ações deste instrumento de prevenção e possibilitar a possível ampliação deste em outros estabelecimentos de ensino para alcançar o maior número possível de estudantes.

Estudos apresentados por Massardi (2013) abordam que a criminalidade está diretamente relacionada ao tráfico de drogas, e este, por sua vez está atingindo principalmente os adolescentes que começam muito cedo a usar algum tipo de entorpecentes. Por conta disso, apresenta-se a prevenção como uma ação que parece apresentar maior eficácia na resistência ao uso destas substâncias, levando o indivíduo a refletir sobre as possíveis ofertas. Mediante estes estudos, pode-se questionar se antes que as drogas sejam ofertadas os jovens sabem das reais consequências e se o novo conhecimento torna-os mais preparados para evitar o contato direto com elas.

Nesse sentido, a pesquisa visa contribuir na elaboração de estratégias que possam fortalecer a tomada de decisão e a escolha de comportamentos positivos, levando os estudantes a pensar sobre a situação, analisar as escolhas, decidir de forma confiante e avaliar sua postura diante de situações que exijam maior reflexão sobre determinadas questões. É nessa linha de pensamento que o Proerd pode ajudar na identificação de comportamentos que possam comprometer a saúde física e mental quanto ao uso de drogas, atuando de forma a auxiliar na tomada de decisão, ou seja, despertando uma postura crítica diante do uso de drogas, buscando reduzir a vulnerabilidade e fortalecer a autonomia dos sujeitos.

Pelo que foi discutido anteriormente, pode-se perceber a necessidade de ampliar o debate sobre a prevenção, haja visto que é um assunto que trará questionamentos acerca do uso de substâncias químicas, pois pelo que está sendo abordado o trabalho preventivo aparece como necessário para instruir os jovens e prepará-los para resistirem às possíveis ofertas. 
Percebe-se que a escola destaca-se como um local de ensinamentos, de estudos, instruções e saberes. É na escola que cada ser humano traz consigo a vontade de aprender, e com isso adquire competências, habilidades e capacidades, que lhes permitirão realizar-se como pessoa, como cidadão e como trabalhador. Assim, é nessa perspectiva que se faz necessária uma abordagem preventiva quanto ao uso de drogas no ambiente escolar para que estes não percam esse foco de construção do conhecimento e fortaleçam cada vez mais suas habilidades e expectativas de vida.

Melo (2013) faz uma consideração aos fatores de risco no ambiente escolar em relação ao uso de drogas. Ele aborda questões como baixo rendimento escolar, falta de vínculo com aprendizagem e exclusão social. De acordo com os aspectos discutidos pelo autor, percebe-se que a prevenção é algo essencial e que deve ter início na escola, para fortalecer vínculos afetivos, minimizar os prejuízos quanto ao rendimento das atividades escolares e proporcionar aos jovens oportunidades para exercer a cidadania.

Nunes (2012) também contribui abordando as ações constantes e abrangentes para fortalecer o instrumento de capacitação e o trabalho de prevenção, envolvendo família, escola e comunidade. O que o autor traz em seu discurso faz uma referência quanto à identificação dos fatores de risco para os jovens, buscando orientá-los a partir da concepção de que é melhor evitar que curar. Essa lógica refere-se ao trabalho preventivo, objetivando antecipar-se às ofertas de drogas na vida dos jovens, levando-os a adquirir a capacidade de resistência através da aquisição de conhecimentos específicos sobre o assunto, pelo fortalecimento da autoestima, substituição do medo pela afirmação da saúde integral, do bem-estar completo do adolescente como um ser autônomo, capaz de tomar decisões seguras sem correr os riscos proporcionados pelo uso de substâncias psicoativas.

Partindo desse pressuposto, este trabalho tem como objetivo geral investigar a atuação do Proerd na prevenção ao uso de drogas nas instituições de ensino fundamental da Região do Cariri/CE, comparando a percepção e o consumo entre adolescentes de escolas onde o Proerd desenvolveu intervenções e aqueles cujas escolas ainda não foram contempladas pelo programa. Quanto aos objetivos específicos da pesquisa busca-se caracterizar o Programa e sua atuação nas escolas, partindo da escuta dos estudantes atendidos pelo programa em relação a sua participação no curso, também identificar a contribuição deste para os fatores de proteção e redução da vulnerabilidade quanto ao uso de drogas e fazer um comparativo do uso entre os educandos concludentes do Proerd com aqueles que não tiveram a oportunidade de participar.

Por esse instrumento de prevenção, veicula-se a possibilidade de uma abordagem diretiva e eficiente, podendo despertar nos jovens uma consciência crítica referente ao uso de drogas, estabelecendo vínculos e buscando proporcionar melhor qualidade de vida para eles e seus familiares. 


\section{Drogas: Definição e Classificação}

O uso abusivo de drogas é algo que aflige a sociedade. As pessoas acabam tornando-se vítimas, mesmo sem usar estas substâncias. As drogas não prejudicam somente a vida de quem as usa, mas passa a comprometer todas as pessoas envolvidas direta e indiretamente com o consumidor.

Para o Programa Educacional de Resistência às Drogas e à Violência, as drogas são definidas como qualquer substância que não seja alimento e que altere o funcionamento do corpo e da mente (PROERD, 2014). Diante desta definição, ao falar de drogas, fala-se de algo que pode comprometer a saúde física e mental do ser humano.

O Observatório Brasileiro de Informações sobre Drogas (OBID) relata que segundo a Organização Mundial de Saúde (OMS) o termo drogas abrange "qualquer substância não produzida pelo organismo que tem a propriedade de atuar sobre um ou mais de seus sistemas, produzindo alterações em seu funcionamento" (BRASIL, 2010, p. 91).

Comparando o que os autores trazem, percebe-se que ambas abordam questões causadoras de alterações físicas e psíquicas no indivíduo, independente do que se está usando, ou seja, não há um componente específico. Neste contexto, pode-se acreditar que ao usar algum tipo de droga, sua continuidade dependerá da forma como esta será administrada pelo próprio usuário.

De acordo com a Secretaria Nacional de Políticas Sobre Drogas (SENAD), na edição que aborda as drogas psicotrópicas, o termo droga teve origem na palavra droog (holândes antigo) que significa folha seca, isso porque antigamente quase todos os medicamentos eram feitos à base de vegetais (BRASIL, 2011).

Em Brasil (2013) as drogas estão classificadas em três grupos, de acordo com a atividade que exercem em nosso cérebro.

No primeiro grupo estão as depressoras da atividade do Sistema Nervoso Central, as quais atuam no cérebro fazendo-o trabalhar mais lento, podendo-se destacar:

[...] o álcool; soníferos ou hipnóticos (drogas que promovem o sono), sendo estas os barbitúricos, alguns benzodiazepínicos; ansiolíticos (acalmam e inibem a ansiedade). As principais drogas pertencentes a esta classificação são os benzodiazepínicos. Ex.: diazepam, lorazepam etc. Além dessas, cita-se também os opiáceos ou narcóticos (aliviam a dor e dão sonolência). Ex.: morfina, heroína, codeína, meperidina etc. Também estão nesta classe os inalantes ou solventes: colas, tintas, removedores, etc. (BRASIL, 2013, p. 9).

O segundo grupo traz as estimulantes da atividade do Sistema Nervoso Central. Essas também atuam no cérebro, passando a acelerar o funcionamento. Destaca-se entre estas: "os anorexígenos (diminuem a fome). As principais drogas pertencentes a essa classificação são as anfetaminas. Também estão nessa classe a cocaína, crack e merla" (BRASIL, 2013, p. 9). 
Em relação ao terceiro grupo estão as perturbadoras da atividade do Sistema Nervoso Central, as quais ao afetar o cérebro fazem com que ele trabalhe de forma desordenada. Geralmente são de origem natural e, segundo Brasil (2013, p. 9) pode ser a "mescalina (do cacto mexicano). THC (da maconha). Psilocibina (de certos cogumelos). Lírio (trombeteira, zabumba ou saia-branca). De origem sintética LSD-25. "Êxtase". Anticolinérgicos, como o Artane e Bentyl".

Todas estas substâncias citadas foram classificadas mediante estudos comprobatórios e divulgados pela SENAD através do manual sobre drogas psicotrópicas.

Mediante esta classificação, ainda pode-se acrescentar que as drogas dividem-se em lícitas (cigarro e bebidas alcoólicas, que têm sua produção, comercialização e consumo regulamentados pelo Estado), e ilícitas (maconha, cocaína, crack, dentre outras proibidas por lei tanto para comercializar quanto para consumir).

Diante de tantas substâncias com efeitos nocivos à saúde, reforça-se a importância do trabalho preventivo, pois antes que estas venham ser consumidas pelos jovens, se faz necessário que estes tenham o conhecimento para resistir às ofertas e à procura, podendo evitar transtornos e garantir uma melhor qualidade de vida. Sendo assim, este trabalho deve iniciar-se ainda na escola, pois é nessa faixa etária que os estudantes passam a ser alvo daqueles que almejam o aliciamento de novos usuários para consumir e repassar drogas, objetivando a prevalência do tráfico.

\section{Programa Educacional de Resistência Às Drogas e à Violência (PROERD): Breve Histórico}

Segundo o histórico do Proerd (2014) o Programa é uma adaptação brasileira do programa norte-americano Drug Abuse Resistence Education (D.A.R.E.) ou D.A.R.E. América, surgido em 1983 na Cidade de Los Angeles, Estados Unidos, criado por psicólogos, pedagogos e policiais especialistas em prevenção, através de uma parceria entre o Distrito Escolar Unificado e o Departamento de Polícia daquela cidade.

Loos (2003) relata que no Brasil, ele foi implantado em 1992, pela Polícia Militar do Estado do Rio de Janeiro (PMERJ), a qual tinha interesse em desenvolver um projeto de prevenção relacionado aos diversos aspectos das drogas. Surgiu então a denominação de PROERD (Programa Educacional de Resistência às Drogas).

De acordo com Ceará (2015) em seguida, no ano de 1993 o programa foi recepcionado pela Polícia Militar de São Paulo (PMSP) e passou a se chamar "Programa Educacional de Resistência às Drogas e a Violência", sendo incluído o tema violência, porém mantendo a sigla PROERD. Afirma ainda que o Programa é desenvolvido atualmente pelas Polícias Militares de todo o Brasil e que para o desenvolvimento, o Proerd possui como material didático o livro do estudante e o manual do instrutor, os quais servem de base para auxiliar os alunos e instrutores.

11 Id en line Revista de Psicologia. Ano 9, No. 28. Novembro/2015 - ISSN 1981-1179. Edição eletrônica em http://idonline.emnuvens.com.br/id 
Segundo Loos (2003) o objetivo desse trabalho consiste em prevenir o uso e abuso de drogas, lícitas e ilícitas, bem como a violência entre estudantes, ajudando-os a reconhecer às pressões do dia a dia e a desenvolver habilidades de resistência diante de fatores que possam colocar a saúde em risco.

No Estado do Ceará, o Programa teve início em março de 2001, por iniciativa do Presidente da SOAPOL (Associação dos Amigos da Polícia Militar do Ceará), o Coronel Professor PM da reserva Remunerada Francisco Austregésilo Rodrigues Lima (CEARÁ, 2015). No ensejo foram formados os primeiros 27 instrutores, pela equipe de mentores de Santa Catarina e São Paulo.

A Polícia Militar do Ceará (2015) destaca aspectos cooperativos do trabalho desenvolvido pelo Proerd, afirmando que:

\begin{abstract}
O programa consiste assim, em uma ação conjunta da Polícia Militar, através do Policial Proerd; da escola, através de professores, especialistas e estudantes; e família, representada pelos pais e pela comunidade de modo geral. Todos unidos no sentido de prevenir e reduzir o uso indevido de drogas e a violência entre estudantes, bem como ajuda-los a reconhecerem as pressões e a influência diária para usarem drogas e praticarem a violência, e a resistirem a elas (CEARÁ, 2015).
\end{abstract}

Destaca-se, portanto, a importância das parcerias entre a Família, a Escola e a Polícia Militar. A consolidação dessa rede de instituições proporciona aos alunos melhores condições para reconhecerem que podem sofrer pressões e influências externas, podendo fortalecer o poder de resistência às ofertas de drogas.

\title{
Prevenção ao uso de Drogas
}

Loos (2003, p. 145) expõe que as atividades de prevenção ao uso de drogas devem ser desenvolvidas de "forma sistêmica e contínua" para viabilizar o processo de comunicação social. Diz ainda que estas ações de prevenção, se de forma específica e "voltada para a transmissão de informações, servem de base para a criação de atitudes, valores e consolidação do comportamento" (LOOS, 2012, p. 145).

Assim, acredita-se que a prevenção se insere em um contexto mais amplo de educação, com direcionamento exatamente para uma abordagem construtiva entre o facilitador e o público alvo, podendo estabelecer uma relação de aceitação ao que é proposto.

Silva (2014) compartilha dizendo que a prevenção deve ser praticada por pessoas preparadas, pois uma intervenção mal feita poderá trazer danos à comunidade e reduzir os benefícios. Complementa falando que o uso indevido de drogas psicoativas deve ser prevenido utilizando métodos e técnicas cientificamente adequadas a cada público alvo, em cada situação e em determinado momento. 
O autor ainda nos alerta sobre alguns princípios que devem ser observados para a realização do trabalho preventivo, dentre os quais se destacam: o processo de prevenção de caráter reflexivo, contínuo, paciente, consistente, provocante no intuito de despertar respostas criativas no público alvo, inovador, agradável para proporcionar o prazer pelo conhecimento nos participantes, devendo também ser multidisciplinar, além de envolver a família e a escola na discussão para garantir que os jovens permaneçam longe das drogas (SILVA, 2014).

Visando melhorar o trabalho de prevenção às drogas no Ceará, o Governo do Estado resolveu institucionalizar o Proerd na Polícia Militar, dando-lhe amplos poderes para o pleno desenvolvimento do programa através do Decreto $\mathrm{n}^{\circ} 28.232$ de 04 de maio de 2006.

Pelo que foi exposto até o momento quanto ao programa de prevenção e a forma como ele é desenvolvido, percebe-se que o mesmo parece representar o caminho mais curto para manter os jovens estudantes conscientes dos malefícios que as drogas podem causar e direcioná-los a resistirem às ofertas além de diminuir a procura.

Portanto, o programa de prevenção em estudo visa combater tendências aliciadoras no ambiente escolar, ajudando os jovens a perceber que tem escolhas e que podem ser felizes sem o uso de drogas, podendo estes desenvolver novos e bons relacionamentos.

Para isto, o Programa Educacional de Resistência às Drogas e à Violência (PROERD) atua no empoderamento dessas informações para o bem comum, atendendo os estudantes em seu habitat, a escola, através de um processo educativo contínuo e eficiente, proporcionando a eles a oportunidade de atuarem como multiplicadores no grupo familiar.

\section{Tipos de Prevenção}

Noto e Galduróz (1999) vêm afirmar que existem diferentes tipos de prevenção no Brasil. Os autores ainda acrescentam que "as ações preventivas ao uso indevido de drogas podem acontecer em diferentes níveis, dependendo da população-alvo e do perfil da intervenção" (NOTO E GALDURÓZ 1999, p. 5). Cassimiro (2009) também contribui destacando a prevenção primária, prevenção secundária e a prevenção terciária como os tipos de prevenção mais conhecidas.

Estudos da Organização Mundial de Saúde - OMS (1992) apud Noto e Galduróz (1999) definem os tipos de prevenção como:

Prevenção primária: É o conjunto de ações que procuram evitar a ocorrência de novos casos de uso abusivo de psicotrópicos ou até mesmo um primeiro uso. Esse tipo de intervenção pode ser realizado dentro de diferentes enfoques, sendo a divulgação de informações o mais conhecido. (NOTO E GALDURÓZ 1999, p. 6). 
Prevenção secundária: É o conjunto de ações que procuram evitar a ocorrência de complicações para as pessoas que fazem uso ocasional de drogas e que apresentam um nível relativamente baixo de problemas. Essas ações buscam sensibilizar as pessoas a respeito dos riscos, favorecendo a mudança de comportamento através do aprendizado de novas atitudes e escolhas mais responsáveis. Prevenção terciária: É o conjunto de ações que, a partir de um problema existente, procura evitar prejuízos adicionais e/ou reintegrar na sociedade os indivíduos com problemas sérios. $\mathrm{Na}$ prática, essas ações envolvem o identificar e o lidar com casos emergenciais (como síndrome de abstinência, overdose, tentativas de suicídio, etc.) e/ou com pacientes portadores de problemas que necessitam encaminhamento (hepatite, AIDS, cirrose, entre outros). Também envolvem a orientação familiar e o auxílio na reabilitação social dos usuários. (NOTO E GALDURÓZ 1999, p. 6).

Nesse contexto, pode-se observar que os tipos de prevenção especificados pelos autores se distinguem pela forma de abordar o tema e o modo como este é desenvolvido mediante os objetivos propostos. Assim, cada nível proporciona uma abordagem diferenciada para melhorar a qualidade de vida do indivíduo, desde evitar o uso até ajudá-lo a lidar com o vício e evitar maiores prejuízos.

Em relação à prevenção primária, Cassimiro (2009) comenta que:

[...] a intervenção primária destina-se a duas faixas etárias: 1) Jovens, dando-se atenção aos problemas da infância e da adolescência em todos os seus aspectos (fisiológicos, psicológicos e socioculturais) e, desse modo, incluindo todos os jovens e não somente àqueles que se consideram como susceptíveis ao uso da droga; e 2) Adultos, fornecendo a estes os conhecimentos básicos que lhes permitam orientar aos jovens, levando-os a refletir sobre a questão e a se engajarem, assumindo o papel de educadores. (CASSIMIRO, 2009, p. 21-22).

Quanto à prevenção secundária, a autora diz o seguinte:

A prevenção secundária, um prolongamento da primária, só deve ser aplicada nos casos em que a primeira não teve êxito e o consumo de drogas já está ocorrendo. Tendo como objetivo evitar que o jovem possa evoluir para um estado de dependência da droga, essa é uma intervenção especializada, que se destina aos que manifestam sinais de dificuldade com os psicotrópicos, como nos casos do jovem que está consumindo drogas por curiosidade ou se encontra com dificuldades pessoais, familiares e/ou sociais, em razão do consumo intermitente no qual, apesar de ainda não ser um dependente, existe o risco de se tornar mais um (CASSIMIRO, 2009, p. 23).

Ao falar da prevenção terciária, relata que:

A prevenção terciária, por sua vez, pressupõe-se que a dependência do uso de drogas já esteja instalada. Tem como objetivo central evitar a recaída após o tratamento, buscando dar ao usuário novas oportunidades de engajamento na escola, na família, enfim, no pequeno grupo de amigos e pessoas com as quais mantém relações afetivas, visando sua reintegração no meio social e trabalhando em três etapas distintas: antes, durante e depois do tratamento. (CASSIMIRO, 2009, p. 23).

Pela abordagem que Cassimiro (2009) faz aos tipos de prevenção, observa-se que é algo sequenciado, pois cada tipo de intervenção proporciona uma abordagem diferenciada de acordo com o objetivo, usuário e perspectivas futuras em relação a cada abordagem. 
Embora esses tipos de prevenção apareçam como estratégia eficaz para evitar ou diminuir o uso de drogas, Noto e Galduróz (1999, p. 7) acrescentam que "estruturação e, especialmente, a integração dos diferentes níveis de intervenção constituem-se o grande desafio para o futuro".

Apesar de todos esses modelos, a autora fala que o critério mais importante para escolher o modelo adequado é conhecer e respeitar as características da comunidade onde se pretende atuar. Portanto, é nesse contexto que o Proerd se encaixa, pois tem a proposta de trabalhar o indivíduo, levando-o a refletir sobre suas decisões e avaliar suas atitudes, estimulando a reflexão sobre a qualidade de vida sem o uso de drogas.

Destacando a prevenção primária, que é base do Proerd, Greco Filho e Rassi (2007) apud Cassimiro (2009, p. 21) afirmam que esta deve anteceder-se ao problema e para tanto, deve atentar para alguns pontos, tais como: "ser precoce; estar inserida em uma visão mais ampla de educação para a saúde e se apoiar nos chamados educadores naturais, em especial os pais e os professores".

Noto e Galduróz (1999) e Brasil (2010) relatam que o objetivo da prevenção primária é evitar que o uso se instale ou retardar o seu início. Atualmente fala-se em níveis de prevenção universal, que são programas destinados à população em geral, supostamente sem qualquer fator associado ao risco; prevenção seletiva com ações voltadas para população com um ou mais fatores associados ao risco de uso de substâncias; prevenção indicada, especificamente com intervenções voltadas para pessoas identificadas como usuárias ou em comportamento de risco, relacionados direto ou indiretamente ao uso de drogas.

Em meio aos diferentes níveis de prevenção citados, reportamo-nos ao nível de prevenção universal, pois está mais diretamente relacionado ao trabalho desenvolvido pelo Proerd, com ações direcionadas à comunidade, ambiente escolar e nos meios de comunicação, através de um planejamento com objetivo comum, atuando de forma coordenada, para que o processo de mobilização ocorra mais facilmente.

Canguilhem (1990) apud Arantes (2008, p. 192) traz a questão de que "aceitar um determinado conceito ou ideia de saúde implica escolher certas intervenções sobre o corpo e a vida dos sujeitos”. Em análise a esta abordagem, pode-se refletir sobre a necessidade de implantar uma ação preventiva tanto na vida pessoal como social do sujeito, sendo esta denominada inicialmente de prevenção primária, a partir de uma mudança de hábitos ou práticas, proporcionando um entendimento focado na pessoa e seu comportamento.

Diante desses questionamentos Carlini (2013, p. 8) alega que "para diminuir este índice e manter os jovens longe das drogas deve-se analisar a situação, definir objetivos e montar um plano de ação, podendo, desse modo, aumentar consideravelmente as chances de sucesso". Na perspectiva da autora, veicula-se uma maior probabilidade para diminuir os fatores de risco e vulnerabilidade entre os jovens. 


\title{
Fatores de Risco e Vulnerabilidade
}

Para Paulilo (2000) o crescimento do consumo de substâncias químicas aponta para a existência de um mercado de drogas clandestino que produz, distribui e comercializa seu produto.

\begin{abstract}
Os jovens têm sido apontados, no mundo todo, como grupo mais suscetível ao uso de drogas. Parte-se da ideia de ser esta faixa etária mais suscetível a comportamentos de risco, de um modo geral. Isso decorre das características comuns a esta fase da vida, apontadas por diferentes áreas do conhecimento. Citamos algumas: momento de transitoriedade e, portanto, de ambiguidade (nem criança, nem adulto); autonomia e responsabilidade relativas; conflito com o mundo adulto (necessidade de opor-se para auto afirmar-se no processo de construção de identidade); crise potencial com emergência de um novo corpo, nova imagem de si mesmo e vivência da sexualidade; sentimento de vulnerabilidade e potencialidade para autodestruição; ansiedade frente às exigências pouco definidas e às demandas difíceis de serem cumpridas em relação à família, trabalho, lazer e consumo. (PAULILO 2000, pág. 42).
\end{abstract}

O que a autora traz em relação aos fatores de risco que cercam os jovens nos remete à ideia de que esse grupo específico está vulnerável ao uso de drogas. Assim, vem cada vez mais comprovar a importância do trabalho preventivo para essa faixa etária. Portanto, necessitam deste apoio através da informação para ficarem longe de drogas e valorizar a vida, buscando outros meios de satisfazerem seus desejos e/ou estabelecer vínculos afetivos saudáveis na busca pela identidade.

Além da abordagem anterior, Paulilo (2000) ainda diz que como categoria sociohistórica a juventude apresenta diversidades na sua forma de existir, o que a coloca em diferentes graus de vulnerabilidade em relação às drogas. Para ela isso acontece porque as diferenças de classe, de região, de estilos, coexistem, ao mesmo tempo, com características comuns a esta faixa etária.

É nessa perspectiva que a organização e distribuição de drogas deste mercado expõem ainda as relações socioeconômicas que o sustentam. Não cabe aqui adotar, portanto, a postura ingênua de considerar o uso de drogas como decorrente apenas de mero ato volitivo do indivíduo. Mostra-se evidente a inter-relação e a interdependência existente entre o usuário e o contexto que o circunda. (PAULILO 2000, p. 54).

Como conclusão destes fatos, a autora ainda afirma que dentro dessa abordagem da vulnerabilidade, "resta-nos, finalmente, sublinhar o peso desta, sendo ela programática ou institucional existente em nosso país, cujo reflexo é o não acesso da maioria dos jovens a programas de informação e de prevenção na rede de educação e nos serviços de saúde" (PAULILO, 2000, p. 58).

Por esse motivo, o Proerd, através dos Policias Instrutores não esperam que os jovens venham até eles, mas antecipa-se indo de encontro em seu habitat, a escola, para fortalecer os fatores de proteção. 


\section{Fatores de Proteção}

Castro (2004) aborda que vários são os fatores de proteção que norteiam os jovens quanto ao uso de drogas. É válido saber que para cada fator de risco existe um fator de proteção capaz de ajudálos a resistir às ofertas de drogas, bem como prepará-los para progredir na vida de forma saudável.

Para melhor compreender e tornar-se conhecedor desses fatores de proteção, Castro (2004) apresenta os vários tipos que podem ajudar os jovens a ficar longe das drogas:

1. Fatores individuais de proteção: correspondem as habilidades sociais, cooperação, habilidades para resolver problemas, vínculos positivos com pessoas, instituições e valores, autonomia e autoestima desenvolvida. 2. Fatores familiares de proteção: Pais que acompanham as atividades dos filhos, estabelecimento de regras de conduta claras, envolvimento afetivo com a vida dos filhos e respeito aos ritos familiares; 3 . Fatores escolares de proteção: Realização pessoal, possibilidades de desafios e expansão da mente, descoberta de possibilidades e "talentos" pessoais, prazer em aprender, descoberta e construção de projeto de vida, vínculos afetivos com professores e colegas, oportunidades de participação e decisão, ligações fortes com a escola, boa inserção e adaptação ao ambiente e bom desempenho escolar. 4. Fatores sociais de proteção: Respeito às leis locais, credibilidade da mídia, oportunidade de trabalho e lazer, informações adequadas sobre as drogas e seus efeitos, clima comunitário afetivo, consciência comunitária e mobilização social; 5. Fatores relacionados à droga de proteção: Informações contextualizadas sobre os efeitos, regras e controle para o consumo. (CASTRO, 2004, p.3-7).

Em meio aos fatores de proteção discutidos, destaca-se o familiar, pois:

[...] é função da família, proporcionar que a criança aprenda a lidar com limites e frustrações logo cedo. Crianças que crescem num ambiente com regras claras, geralmente, são mais seguras e sabem o que devem ou não fazer para agradar. Quando se defrontam com um limite, sabem lidar com a frustração, por terem desenvolvido recursos próprios para superá-la. (CASTRO, 2004, p. 04).

Diante desses modelos de proteção, ressalta-se que os modelos de programas de prevenção devem ser desenvolvidos com filosofias definidas, que ofereçam aos alunos informações precisas e que possa despertar, neles, a criticidade diante dos fatos apresentados.

\section{As Políticas Públicas e Atuação do Psicólogo na Prevenção do Uso de Drogas}

As políticas públicas do Sistema único de Saúde (SUS) têm avançado ao longo dos anos na questão da prevenção e promoção da saúde do usuário de drogas. Dentre elas, destaca-se o Centro de Atenção Psicossocial (CAPSad) para usuários de álcool e drogas.

Nessa perspectiva, o Ministério da Saúde (BRASIL, 2004), afirma que os CAPSad devem oferecer atendimento diário a pacientes que fazem uso prejudicial de álcool e outras drogas. Para 
Brasil, esse atendimento proporciona aos usuários o planejamento terapêutico para ocorrer à evolução no tratamento e acontece da seguinte forma:

Os CAPSad desenvolvem uma gama de atividades que vão desde o atendimento individual (medicamentoso, psicoterápico, de orientação, entre outros) até atendimentos em grupo ou oficinas terapêuticas e visitas domiciliares. Também devem oferecer condições para o repouso, bem como para a desintoxicação ambulatorial de pacientes que necessitem desse tipo de cuidados e que não demandem por atenção clínica hospitalar. (BRASIL, p. 24, 2004).

A forma específica de atuação do CAPSad pode levar o indivíduo a planejar melhor a vida com implementação e estratégias que possam promover a promoção em saúde, bem como a redução de fatores que possam levar o indivíduo a um adoecimento por conta das drogas. Neste contexto, o CAPSad pode atuar na prevenção, que pode ser compreendida como um processo de planejamento, implantação e implementação de múltiplas estratégias voltadas para a redução dos fatores de risco específicos e fortalecimento dos fatores de proteção. Prevenir, portanto, é impedir o uso de substâncias psicoativas pela primeira vez e minimizar as consequências do uso.

As estratégias de prevenção devem contemplar a utilização combinada dos seguintes elementos: fornecimento de informações sobre os danos do álcool e outras drogas, alternativas para lazer e atividades livres de drogas; devem também facilitar a identificação de problemas pessoais e o acesso ao suporte para tais problemas. Devem buscar principalmente o fortalecimento de vínculos afetivos, o estreitamento de laços sociais e a melhora da autoestima das pessoas. (BRASIL, 2004, p. 24,).

Pode-se então concluir que, a filosofia preventiva adotada pelo CAPSad corresponde, em parte, ao trabalho desenvolvido pelo Proerd nas escolas através do fornecimento de informações específicas sobre as drogas e empoderamento do conhecimento adquirido. Com isso, podem-se reduzir os fatores de riscos e fortalecer os de proteção. No entanto, tem como diferencial o fato de que o CAPSad atua também no tratamento acolhendo aqueles que necessitam de apoio psicossocial para melhorar a qualidade de vida.

É válido acrescentar que o Proerd foi criado com a participação de psicólogos e assim, faz estreita relação com a Psicologia. Assim pode-se perceber que esse profissional, quando inserido na prevenção do uso de drogas, realiza um trabalho de grande relevância, pois atua diretamente na subjetividade do ser humano, levando o mesmo a refletir sobre os reais efeitos que as drogas podem causar aos usuários além de despertar neles um olhar crítico diante do tema em questão.

Pardal (2007) vem contribuir afirmando que o importante é informar e promover a reflexão a respeito deste tema que é polêmico e complexo. Para tanto, ele destaca que a escola juntamente com a família, é um dos veículos informativos mais importantes para a vida e o desenvolvimento de crianças e adolescentes. 
Apresenta-se como atitudes do psicólogo, estimular a criação de vínculos afetivos, privilegiando o diálogo, mobilizando a família e trabalhar para o empoderamento da autoconfiança e autoestima. Para isso, devem-se evitar atitudes terroristas, preconceituosas, punitivas ou repressivas (PARDAL, 2007).

É, portanto, nesse contexto que o psicólogo pode atuar com mais precisão e obter resultados mais eficazes, seja a curto, médio ou longo prazo.

\section{Método}

A pesquisa foi desenvolvida através do método quantitativo com levantamento de dados para conhecer, de acordo com os objetivos, a atuação do Programa Educacional de Resistência às Drogas e à Violência (PROERD) na prevenção às drogas, em Maio de 2015.

Para Gil (2002) esse tipo de pesquisa se dá pela solicitação de informações a um grupo de pessoas acerca do problema estudado para obtenção das conclusões correspondentes aos dados coletados. Sendo assim, para colher os dados necessários e efetivar a pesquisa, foi desenvolvido um questionário com itens objetivos, a fim de investigar a relação dos alunos com a família, com a escola, além de identificar aspectos ligados à percepção do mesmo quanto às drogas e quanto à experiência no Programa, bem como a exposição e a experimentação de substâncias psicoativas, comparando alunos que participaram do Proerd com aqueles que não participaram.

\section{Informações sobre o Campo e Amostra da Pesquisa}

Participaram da pesquisa 392 alunos cursando o $6^{\circ}$ (sexto), $7^{\circ}$ (sétimo), $8^{\circ}$ (oitavo) e $9^{\circ}$ (nono) anos do Ensino Fundamental, sendo 58,4\% ex-alunos do Proerd e o restante dos alunos não participaram do programa.. Dentre estes, $50,9 \%$ eram do sexo masculino e $49,1 \%$ do sexo feminino. A faixa etária variou entre 10 e 18 anos $(\mathrm{M}=12,9 ; \mathrm{DP}=1,47)$. As entrevistas aconteceram nas seguintes escolas: E.E.F. 18 de dezembro no município de Altaneira (15,3\%), E.E.F. Arara Azul em Caririaçu (15,3\%), E.E.F. Romão Sabiá em Aurora (12,5\%), no Colégio Mundo Mágico (15,3\%) em Juazeiro do Norte, na E.E.F. Josefa Alves em Barbalha (16,5\%) e Colégio Municipal Pedro Felício $(25,2 \%)$.

Assim, os dados serão comparados e posteriormente verificados de acordo com os objetivos pretendidos, pois torna-se importante verificar a atuação do Proerd diante do trabalho preventivo realizado nas unidades escolar para ampliar cada vez mais as ações nessa área. 
Segundo Dalfovo $(2008$, p. 4) "a população de uma pesquisa é como um conjunto que se pretende estudar e o indivíduo uma peça deste conjunto". É por esse motivo que a pesquisa foi delineada para estudantes do Proerd, visando com isso, transmitir um panorama acerca dos trabalhos desenvolvido pelos Policiais Instrutores.

Tabela 1: Descrição do desenho amostral.

\begin{tabular}{|c|c|c|c|c|c|c|c|c|c|c|}
\hline \multirow{3}{*}{$\begin{array}{c}\text { Série } \\
\text { Escolar }\end{array}$} & \multicolumn{4}{|c|}{ Participantes do Proerd } & \multicolumn{4}{|c|}{ Não participantes do Proerd } & \multirow{2}{*}{\multicolumn{2}{|c|}{ Total }} \\
\hline & \multicolumn{2}{|c|}{ M } & \multicolumn{2}{|r|}{$\mathrm{F}$} & \multicolumn{2}{|r|}{ M } & \multicolumn{2}{|r|}{$\mathrm{F}$} & & \\
\hline & $\mathrm{N}$ & $\%$ & $\mathrm{~N}$ & $\%$ & $\mathrm{n}$ & $\%$ & $\mathrm{n}$ & $\%$ & $\mathrm{n}$ & $\%$ \\
\hline $6^{\circ}$ ano & 36 & $9,2 \%$ & 23 & $5,9 \%$ & 35 & $8,9 \%$ & 17 & $4,3 \%$ & 111 & $28,3 \%$ \\
\hline $7^{\circ}$ ano & 27 & $6,9 \%$ & 33 & $8,4 \%$ & 13 & $3,3 \%$ & 16 & $4,1 \%$ & 89 & $22,7 \%$ \\
\hline $8^{\circ}$ ano & 27 & $6,9 \%$ & 33 & $8,4 \%$ & 10 & $2,6 \%$ & 14 & $3,6 \%$ & 84 & $21,4 \%$ \\
\hline $9^{\circ}$ ano & 28 & $7,1 \%$ & 22 & $5,6 \%$ & 24 & $6,1 \%$ & 34 & $8,7 \%$ & 108 & $27,6 \%$ \\
\hline Total & 118 & $30,1 \%$ & 111 & $28,3 \%$ & 82 & $20,9 \%$ & 81 & $20,7 \%$ & 392 & $100,0 \%$ \\
\hline
\end{tabular}

FONTE: Dados da pesquisa

\section{Procedimentos para a Coleta de Dados}

Com o objetivo de proporcionar a veracidade da pesquisa, os equipamentos para coleta e análise dos dados foram pré-organizados de acordo com o referencial teórico para que os resultados estejam em consonância com o que realmente se quer alcançar em termos de atuação do Programa em destaque.

Inicialmente cogitou-se a possibilidade de que o Proerd teria grande influência na vida dos estudantes para que os mesmos permanecessem longe de drogas. Para tanto, observou-se o campo de atuação para ver a possibilidade de realizar as entrevistas necessárias, mediante questionário que comtemplasse os objetivos da pesquisa e pudesse chegar a um resultado. Como análise do campo, acreditou-se que este deveria abranger grande parte da região do cariri, pois o Proerd tem atuação em quase todos os municípios. Na sequência foram programadas as visitas nas escolas que participaram da pesquisa.

\section{Técnicas de Coleta e Análise de Dados}

Os dados coletados através dos questionários foram digitados no programa Microsoft Office Excel e exportados para o Pacote Estatístico de Ciências Sociais (SPSS v. 20). A partir disso, foram realizadas estatísticas descritivas e análises de correlação. Para estas últimas, foi utilizado o teste qui- 
quadrado para verificar a correlação entre as variáveis estudadas, visto que o mesmo corresponde a um teste não paramétrico, adequado para ser aplicado no caso de variáveis nominais ou ordinais (LEVIN; FOX, 2004).

Para Gatti (2004, p. 14) a análise de dados quantitativos constitui-se em um trabalho que propicia "a informação que não pode ser diretamente visualizada a partir de uma massa de dados, poderá sê-lo se tais dados sofrerem algum tipo de transformação que permita uma observação de outro ponto de vista".

\section{Resultados e Discussão}

A pesquisa teve como fonte de investigação alunos que participaram do Programa Educacional de Resistência às Drogas e à Violência (PROERD) para investigar a atuação deste e o quanto contribuiu para qualidade de vida dos estudantes entrevistados. Para saber a relação com o uso de drogas, efetuou-se uma comparação de dados entre as respostas dos jovens participantes do curso com outros que não tiveram a oportunidade de participar do Proerd. Para isso, foi criado um grupo controle, pois desse modo os resultados obtidos podem ser comparados e validados.

O público entrevistado foi selecionado de forma que fosse possível colher a amostra abrangendo grande parte da região do cariri, a qual tem cerca de $80 \%$ dos municípios atendidos pelo Proerd. A tabela a seguir caracteriza a amostra conforme alguns dados sociodemográficos.

Tabela 2: Caracterização da amostra pesquisada.

\begin{tabular}{|c|c|c|}
\hline Participação no PROERD & $\mathbf{n}$ & $\%$ \\
\hline Sim & 229 & 58,4 \\
\hline Não & 163 & 41,6 \\
\hline Total & 392 & 100,0 \\
\hline Sexo & $\mathbf{n}$ & $\%$ \\
\hline Masculino & 200 & 51,0 \\
\hline Feminino & 192 & 49,0 \\
\hline Total & 392 & 100,0 \\
\hline Município & n & $\%$ \\
\hline Juazeiro do Norte & 60 & 15,3 \\
\hline Crato & 99 & 25,3 \\
\hline Barbalha & 64 & 16,3 \\
\hline Altaneira & 60 & 15,3 \\
\hline Aurora & 49 & 12,5 \\
\hline Caririaçu & 60 & 15,3 \\
\hline Total & 392 & 100,0 \\
\hline Série & n & $\%$ \\
\hline $6^{\circ}$ ano & 111 & 28,3 \\
\hline $7^{\circ}$ ano & 89 & 22,7 \\
\hline $8^{\circ}$ ano & 84 & 21,4 \\
\hline $9^{\circ}$ ano & 108 & 27,6 \\
\hline Total & 392 & 100,0 \\
\hline Religião* & n & $\%$ \\
\hline Católica & 319 & 81,8 \\
\hline Envagélica & 60 & 15,4 \\
\hline Outras & 11 & 2,8 \\
\hline Total & 390 & 100,0 \\
\hline
\end{tabular}

* Não responderam: 2 pessoas. FONTE: Dados da pesquisa 
Destaca-se também a religião, por ser importante para obtenção dos dados da pesquisa, pois mostra o perfil da vida religiosa dos jovens, sendo esta uma variável importante e bastante avaliada na literatura sobre adolescência e consumo drogas (DALGALARRONDO et al., 2004; SANCHEZ; NAPPO, 2008; ABDALA et al., 2010; FUNAI; PILLON, 2011; XAVIER, 2012).

Pelo que se descreve, a amostra total foi de 392 jovens, divididos entre 06 (seis) municípios: em Juazeiro do Norte, Altaneira e Caririaçu foram aplicados 60 questionários, em um percentual de $(15,3 \%)$ para cada um deles e Aurora com 49 (12,5\%), todos eles com estudantes que participaram do curso do Proerd. Em relação aos municípios de Barbalha com 64 (16,3\%) entrevistados e Crato 99 $(25,3 \%)$ referencia o grupo controle, ou seja, a amostra daqueles que não estiveram no Proerd. Para cada um destes municípios foi escolhida uma escola participante, em um total de seis. Destas, os $6^{\circ}$ anos tiveram 111 alunos $(28,3 \%)$, os $7^{\circ}$ anos $89(22,7)$, os $8^{\circ}$ anos $84(21,4)$ e os $9^{\circ}$ anos $108(27,6 \%)$.

Deste modo, partindo dos dados citados, $229(58,4 \%)$ frequentaram o curso e $163(41,6 \%)$ não tiveram a oportunidade de participar.

Do total geral, 200 (51,0\%) era do sexo masculino e 192 (49,0\%) feminino.

Referindo-se ao tema religião, 319 (81,8\%) alegaram ser católicos, 60 (15,4\%) evangélicos e $11(2,8 \%)$ confirmaram ser de outras religiões.

Tendo como referência os dados desta tabela, apenas 02 ficaram sem expor a religião a que pertence.

Tabela 3: Prevalência de consumo de álcool e cigarro entre estudantes Proerd e não no Proerd.

\begin{tabular}{ccccc}
\hline Substância & $\begin{array}{c}\text { Alunos } \\
\text { Proerd }\end{array}$ & $\begin{array}{c}\text { Alunos Não } \\
\text { Proerd }\end{array}$ & $\begin{array}{c}\text { Risco } \\
\text { Relativo }\end{array}$ & Estatísticas \\
\hline Álcool & $6,1 \%$ & $29,4 \%$ & 4,8 & $\begin{array}{c}\text { Qui-Quadrado }= \\
37,207 ; \\
\mathrm{p}<0,0001\end{array}$ \\
Cigarro & $1,3 \%$ & $11,7 \%$ & 8,8 & $\begin{array}{c}\text { Qui-Quadrado } \\
17,339 ; \mathrm{p}<0,001\end{array}$ \\
\hline
\end{tabular}

FONTE: Dados da pesquisa 
Gráfico 01: Prevalência de consumo de álcool e cigarro entre estudantes Proerd e não no

Proerd.

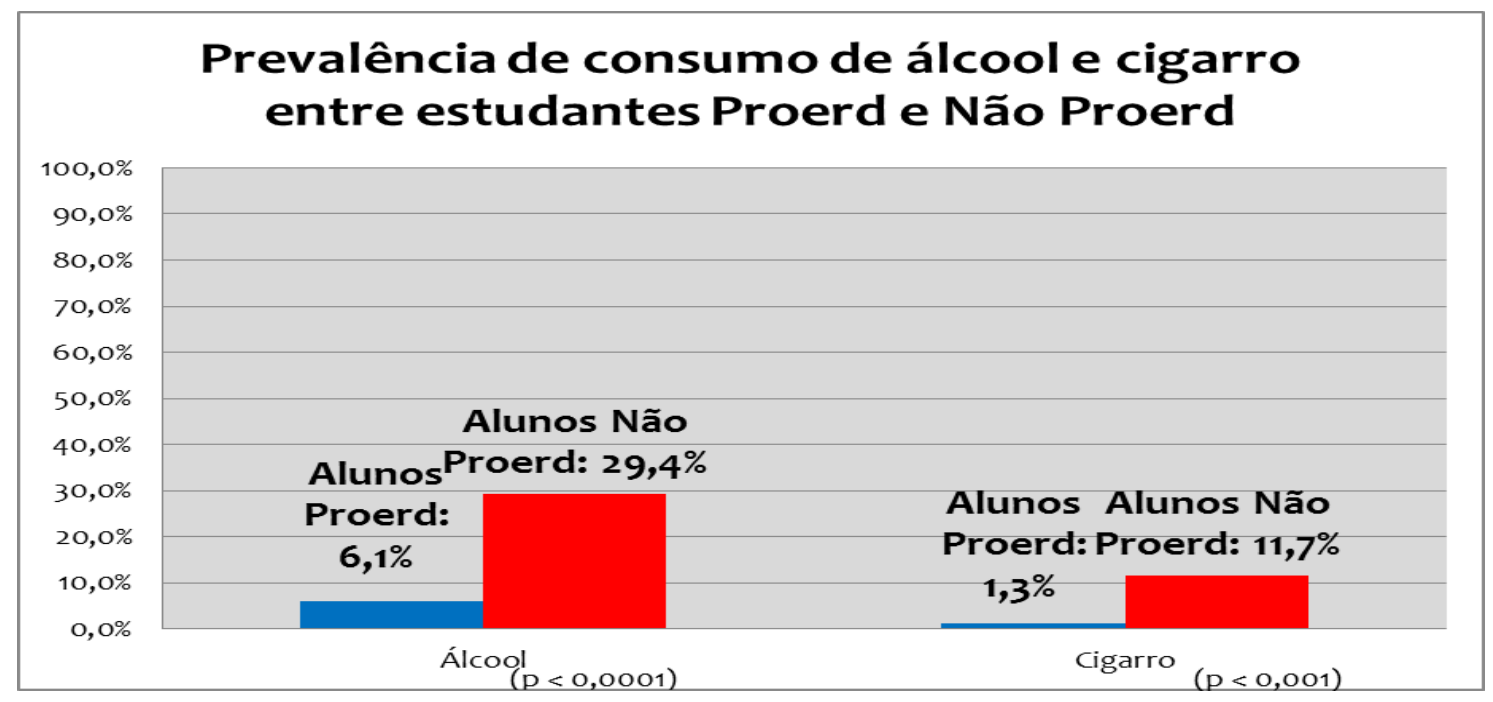

FONTE: dados da pesquisa

Ao investigar a atuação do Proerd na prevenção do uso de drogas, faz-se necessário avaliar o consumo dessas substâncias entre os estudantes. Dentre as drogas citadas, os dados mostram relevância apenas no consumo de drogas lícitas, a bebidas alcoólicas com 6,1\% de uso para os alunos que passaram pelo Proerd e 29,4\% para os que não fizeram Proerd. Quanto ao risco relativo na questão do consumo de álcool entre alunos que não participaram do Proerd excede em 4,8 vezes o de alunos que participaram do programa.

Quanto ao uso de cigarros, o índice foi de 1,3\% para alunos do Proerd e 11,7\% de usuários que não passaram pelo programa. Para esta situação, o risco de consumo de cigarro entre alunos que não participaram do Proerd excede em 8,8 vezes o de alunos que participaram do programa.

Diante destes dados, percebe-se claramente que ao educandos com instruções de prevenção através do curso do Proerd, tem maior probabilidade de ficar longe das drogas e um menor fator de risco.

Tabela 4: Percentual de participantes que afirmaram ter recebido convite para consumir álcool e outras drogas.

\begin{tabular}{ccc}
\hline Substância & $\mathbf{n}$ & $\%$ \\
\hline Álcool & 152 & 38,8 \\
Cigarro & 68 & 17,3 \\
Maconha & 24 & 6,1 \\
Cocaína & 10 & 2,6 \\
Crack & 10 & 2,6 \\
\hline
\end{tabular}

FONTE: Dados da pesquisa 
Gráfico 02: Percentual de participantes que afirmaram ter recebido convite para consumir álcool e outras drogas.

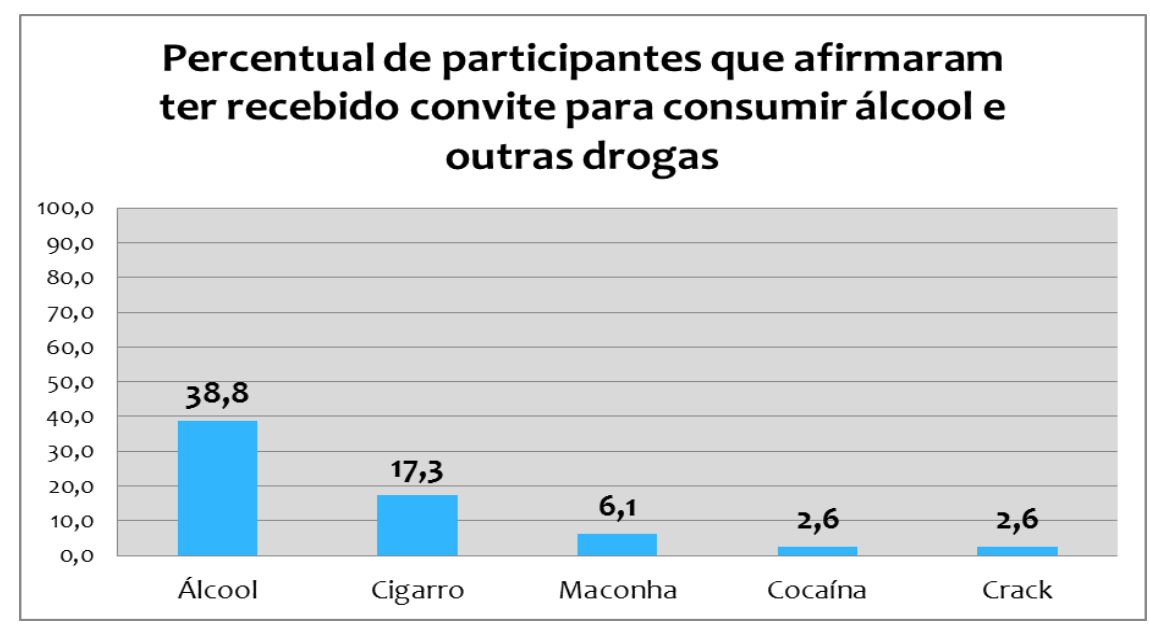

FONTE: Dados da pesquisa

Outra situação que merece atenção é a questão da exposição desses alunos às drogas mediante convites. Como resultado, foram convidados para consumir álcool 152 estudantes $(38,8 \%)$, para usar cigarro $68(17,3 \%)$, maconha $24(6,1 \%)$, cocaína $10(2,6 \%)$ e finalmente o crack com $10(2,6 \%)$. Sabese, porém, que nem todos os alunos para os quais são ofertadas drogas fazem uso, no entanto ao serem convidados para usar, passam a conviver com determinados fatores de risco, sendo que as bebidas alcoólicas tem o maior índice de ofertas.

Tabela 5: Taxa de consumo de álcool conforme avaliação da escola onde estuda, da frequência e da participação dos pais na vida escolar.

\begin{tabular}{lcc}
\hline \multicolumn{1}{c}{ Item avaliado } & Taxa de consumo & Estatísticas \\
\hline Escola onde estuda & $\%$ & \\
Positiva & 34,8 & Qui-quadrado $=4,059 ;$ \\
Negativa & 55,6 & p $<0,05$ \\
\hline Participação dos pais na vida escolar & $\%$ & \\
\hdashline Positiva & 34,8 & Qui-quadrado $=3,186 ;$ \\
Negativa & 56,3 & p $<0,05$ \\
\hline Frequência e participação nas aulas & $\%$ & \\
\hdashline Positiva & 37,4 & Qui-quadrado $=4,185 ;$ \\
Negativa & 77,8 & p $<0,05$ \\
\hline
\end{tabular}

FONTE: Dados da pesquisa 
Gráfico 03: Taxa de consumo de álcool conforme avaliação da escola onde estuda, da frequência e da participação dos pais na vida escolar.

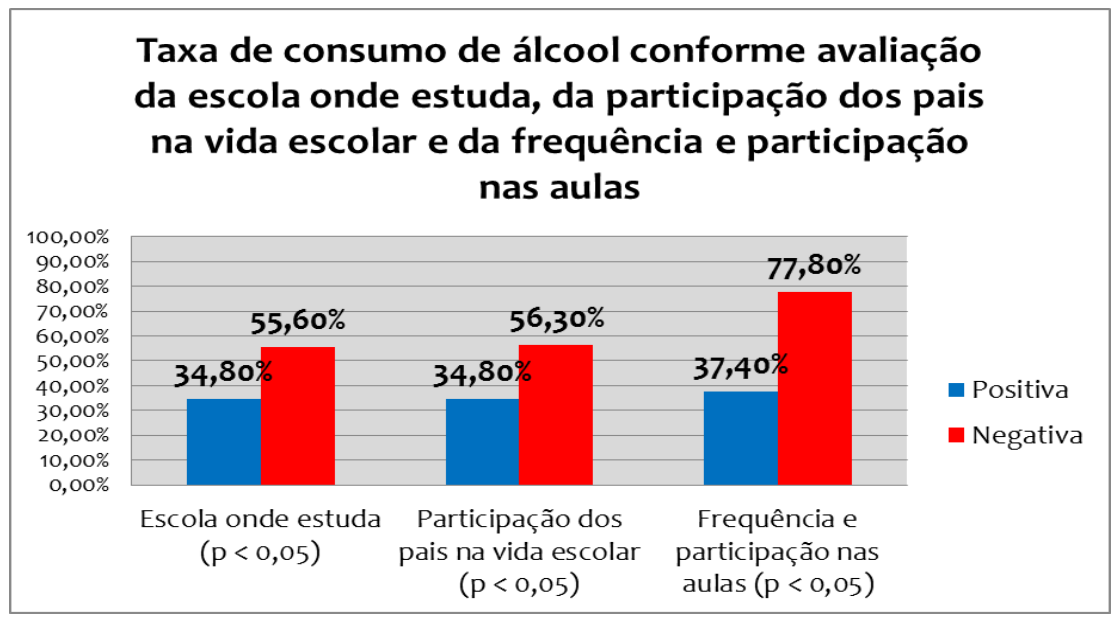

FONTE: Dados da pesquisa

Destaca-se nesta tabela o consumo de álcool, por ter sido os resultados de maior significância em relação à avaliação que os estudantes fazem da escola que estuda, também a participação dos pais na vida escolar deles, além de verificar a frequência e participação destes nas aulas.

Ao avaliarem a escola que estudam, responderam ser positiva $34,8 \%$, referente à taxa de consumo. Como avaliação negativa, a taxa foi de 55,6\%. Portanto, percebe-se que quanto melhor a avaliação da escola menor a taxa de aceitação do álcool.

Sobre a participação dos pais na vida escolar, $34,8 \%$ disseram ser positiva. Relataram ser negativa 56,3\%. Nessa abordagem, os resultados mostram que a avaliação daqueles que falaram ser positiva a participação dos pais, o consumo de álcool é bem menor.

Ao verificar a frequência e participação nas aulas, o índice de aprovação foi de 37,4\% de uso. A avaliação negativa teve taxa de $77,8 \%$. Sendo assim, aqueles que têm boa frequência e participa ativamente das aulas, tem menor chance de se envolver com bebidas alcoólicas.

Investigou-se também o consumo de outras drogas: cigarro, maconha, cocaína e crack, porém não houve nenhuma correlação significativa nas estatísticas, sendo organizada na tabela apenas a correlação com o álcool, pois esta se mostra bastante significante para a pesquisa.

Para se chegar a tais conclusões, foi necessário traçar o perfil dos alunos em diversas correlações, no entanto, estas não foram descritas em tabelas pela insignificância dos resultados. Apesar de não uma correlação estatisticamente significativa entre algumas variáveis, merecem ser discutidas para fins de reflexão.

Religião (católica $\mathbf{X}$ evangélica) $\mathbf{X}$ Consumo: o que os resultados mostraram foi um consumo levemente maior de drogas lícitas (álcool e cigarro) entre evangélicos, enquanto os católicos foram os únicos que relataram ter consumido drogas ilícitas (maconha, cocaína e crack). Os resultados 
nesta área não são muito conclusivos. Dalgalarrondo et al. (2004) apresentam uma extensa revisão de literatura que aponta para um maior uso de álcool e drogas entre adolescentes e jovens que não têm religião, que têm pouca crença religiosa e que não frequentam igreja e cultos. No entanto, Funai e Pillon (2011), em pesquisa com estudantes de enfermagem, não encontraram correlação significativa entre religiosidade e consumo de drogas. Percebe-se que maiores investigações devem ser realizadas para compreender melhor esse contexto.

$\checkmark$ Grau de religiosidade X Consumo: os resultados se mostraram significativos apenas para o consumo de álcool. Ou seja, aqueles que se consideram nada ou pouco religiosos apresentaram risco quase duas vezes maior $(\mathrm{RR}=1,8 ; \mathrm{p}<0,005)$ de consumirem álcool em relação àqueles que se declararam muito religiosos. Já no que tange às outras substâncias, não foram observadas diferenças significativas.

$\checkmark$ Consumo dos Pais X Consumo dos Filhos: os resultados não se mostraram significativos. Em relação ao álcool, aqueles adolescentes cujos pais não consumiam ou consumiam raramente, experimentaram mais do que aqueles cujos pais consumiam com regularidade $(17,1 \%$ e $14,5 \%$ respectivamente - diferença não significativa estatisticamente). Em relação ao cigarro, também não houve diferença expressiva, tendo os adolescentes cujos pais consumiam com regularidade, experimentado em maior proporção do que aqueles cujos pais que não consumiam $(7,2 \%$ e 4,6\% respectivamente - diferença não significativa estatisticamente).

Quanto ao uso de cigarro, percebe-se que os resultados foram diretamente proporcionais, pois quanto mais regular o uso pelos pais, maior o consumo dos filhos, de modo que pais com menor regularidade de uso os filhos também tem menor índice de consumo. Vale ressaltar que os resultados obtidos nesta pesquisa servirão para desenvolvimento de futuros trabalhos acadêmico, dentre estes dissertação de mestrado e tese de doutorado.

Sendo a escola um veículo de informação, capacitação e formação, Tiba (2007, p.202) relata que "a escola tem por obrigação capacitar-se para enfrentar o maior mal evitável do século, as drogas. Queira ou não, seus alunos entrarão em contato com drogas (...)”. Assim, a escola, por meio de seus educadores precisa ajudar os jovens na formação de uma consciência crítica acerca do uso de substâncias maléficas à saúde.

\section{Considerações Finais}

Na construção deste trabalho buscou-se evidenciar o Programa Educacional de Resistência às Drogas e à Violência (PROERD) como um percussor na prevenção do uso de drogas. Este Programa destaca-se pela forma como é desenvolvido nas instituições de ensino, através de um modelo dinâmico de educar e prevenir. As ações são voltadas para jovens em seu habitat, a escola, e 
atua principalmente na prevenção primária, ou seja, evitar o uso de drogas para aqueles que ainda não experimentaram ou simplesmente provaram em um determinado momento da vida.

As ações do Programa visam proporcionar a interação de todos na resistência às ofertas de drogas. Assim, o Policial Militar Instrutor atua como facilitador, visando estabelecer uma relação de confiança para levar aos discentes o conhecimento sobre o assunto, ao mesmo tempo em que visa o empoderamento destes para uma vida mais saudável. Diante da pesquisa realizada neste trabalho e dos resultados apresentados, conforme está descrito nas tabelas e comentados, destaca-se o desempenho positivo do Proerd.

Referindo-se a aplicação do Programa, este tem como fundamento despertar a reflexão sobre o uso de substâncias químicas através da problematização, debater sobre maneiras saudáveis de viver, trabalhar as relações afetivas entre os estudantes, resistir às pressões de grupo e incentivar o respeito às normas sociais.

Para tanto, a meta alcançada partiu do objetivo de investigar a atuação do Programa na prevenção ao uso de drogas em instituições de Ensino Fundamental da Região do Cariri/CE. Partiu também da necessidade de identificar os fatores de proteção e redução da vulnerabilidade, além de comparar questões referentes ao uso de drogas entre estudantes que participaram e/ou não do Proerd.

Como objeto de estudo, visando conhecer, avaliar e validar os resultados do trabalho desenvolvido pelo Programa, esta pesquisa poderá contribuir para ampliação deste em outros municípios e manter crianças e adolescentes longe de drogas.

Portanto, pelo que foi discutido, o Proerd se mostrou como uma estratégia eficaz na prevenção ao uso de álcool e cigarro, no entanto, há riscos em relação ao consumo dessas substâncias quando ofertadas aos alunos, sendo as bebidas alcoólicas o maior deles com 4,8 vezes a mais para os que não participaram do Proerd. Quanto ao cigarro, o risco relativo é de 8,8 vezes para aqueles que não tiveram as instruções do Proerd, enquanto que para as outras drogas não se pode afirmar algo conclusivo, necessitando de maiores investigações.

\section{Referências}

ABDALA, Gina Andrade; RODRIGUES, Wellington Gil; TORRES, Amilton; RIOS, Mino Correia; BRASIL, Mágela de Souza. A Religiosidade/Espiritualidade como influência positiva na abstinência, redução e/ou abandono do uso de drogas. Revista de Estudos da Religião, p. 77-98, mar/2010.

ARANTES, Rosalba Cassuci. et. al. Processo saúde-doença e promoção da saúde. Aspectos históricos e conceituais. Ver. APS, v. 11, nº 2, p. 189-198. Abril/junho, 2008.

AZEVEDO, Gilson Xavier. Estreitamentos bibliográficos entre consumo de drogas, família e religião. In: ECCO, Clóvis; MACHADO, Erika Pereira; FERREIRA, Joel Antônio; SILVA, Rosemary Francisca Neves. (orgs). Transformação Social, Economia e Literatura Sagrada. Goiânia: Ed. PUC- 
Goiás/América. VI Congresso Internacional em Ciências da Religião - XIII Semana de Estudos da Religião, 2012.

BRASIL. Lei 11.343 de 23 de agosto de 2006. Institui o Sistema Nacional de Políticas Públicas sobre Drogas - Sisnad. Disponível em: www.planalto.gov.br. Acesso em 10 de setembro de 2014, as $15 \mathrm{~h} 00 \mathrm{~min}$.

- Secretaria Nacional de Políticas Sobre Drogas. Ministério da Justiça. Curso de prevenção do uso de drogas para educadores de escolas públicas. $4^{a}$ ed. Brasília, 2010, pág. 138-139.

Ministério da Saúde. Secretaria de Atenção à Saúde. Departamento de Ações Programáticas Estratégicas. Brasília-DF, 2004. Disponível em: www.saude.gov.br.

Observatório Brasileiro de Informações Sobre Drogas (OBID). Brasília, 2007. Disponível em: www.obid.senad.gov.br. Acesso em 21 de setembro de 2014, às 17h18min.

Secretaria Nacional de Políticas sobre Drogas. SENAD. Drogas Psicotrópicas. Esplanada dos Ministérios, Bloco T, Anexo II, $2^{\circ}$ andar, sala 207. Brasília DF. $5^{\mathrm{a}}$ edição - $1^{\mathrm{a}}$ reimpressão 2011. Disponível em: www.senad.gov.br.

CARLINI, Beatriz H. Secretaria Nacional de Políticas Públicas sobre Drogas. Série por dentro do assunto- cartilha mudando comportamentos. Brasília - DF. Ministério da Justiça. $2^{\mathrm{a}}$ ed. 2013. Disponível em: www.senad.gov.br. Acesso em 10de setembro de 2014, às 14h30min.

CASTRO, Magali Sampaio. Fatores de risco e proteção na prevenção do uso indevido de Drogas. UFPI, Teresina, 2004.

CASSIMIRO, Regina Magda Alves. A importância da Prevenção na luta contra as drogas. Artigo. Brasília, 2009.

CEARÁ. Histórico do Programa Educacional de Resistência às Drogas e à Violência - PROERD. Polícia Militar do Ceará. 2015. Disponível em: http://www.pm.ce.gov.br/index.php/acoessociais/sociais/proerd. Acesso em 23 de abril de 2015.

DALFOVO, Michael Samir; LANA, Rogério Adilson; SILVEIRA, Amélia. Métodos quantitativos e qualitativos: um resgate teórico. Revista Interdisciplinar Científica Aplicada, Blumenau, v.2, n.4, p.01- 13, Sem II. 2008. ISSN 1980-7031.

DALGALARRONDO, Paulo; SOLDERA, Meire Aparecida; CORRÊA FILHO, Heleno Rodrigues; SILVA, Cleide Aparecida M. Religião e uso de drogas por adolescentes. Revista Brasileira de Psiquiatria, v. 26, n. 2, p. 82-90, 2004.

FUNAI, Anderson; PILLON, Sandra Cristina. Uso de bebidas alcoólicas e aspectos religiosos em estudantes de enfermagem. Revista Eletrônica de Enfermagem, v. 13, n. 1, p. 24-29, jan/mar, 2011.

GATTI, Bernadete A. Estudos quantitativos em educação. Fundação Carlos Chagas. Educação e Pesquisa, São Paulo, v.30, n.1, p. 11-30, jan./abr. 2004.

GIL, Antônio Carlos, 1946. Como elaborar um projeto de pesquisa. $4^{\text {a }}$ ed. São Paulo. Atlas, 2002.

LEVIN, Jack; FOX, James Alan. Estatística para ciências humanas / Statistics for social sciences. São Paulo; Person; 2004. XV, 497 p. tab. graf.

LOOS, Tânia. Projeto multiplicador de ações preventivas. Revisão e adaptação. Rio de Janeiro, 2003, p. 145. 
MASSARDI, Wellington de Oliveira. Análise das implicações do Programa Educacional de Resistência às Drogas e à Violência: o caso das escolas públicas de Ubá. Gestão Contemporânea, Porto Alegre, ano 10, n. 13, p. 149-164, jan./jun. 2013. Disponível em: http://seer2.fapa.com.br/index.php/arquivo.

NOTO, Ana Regina; GALDURÓZ, José Carlos F. O uso de drogas psicotrópicas e a prevenção no Brasil. Ciência \& Saúde Coletiva, vol. 4, núm. 1, 1999, pp. 145-151. Associação Brasileira de PósGraduação em Saúde Coletiva Rio de Janeiro, Brasil, 1999. Disponível em: http://www.redalyc.org/pdf/630/63013483012.pdf. Acesso em 15 de abril de 2015.

NUNES, Barbosa. Maçonaria a favor da vida. Brasília, Grande Oriente do Brasil - GOB. Cap. IV, edição 2012.

PARDAL, Poliana Priscila Matos. As drogas e o papel do Psicólogo Escolar no tratamento e prevenção. Revista Viver Mente e Cérebro, 2007, $\mathrm{n}^{\mathrm{o}}$ 169, ano XVI, 66 / 71. Disponível em: http://meuartigo.brasilescola.com/psicologia/as-drogas-papel-psicologo-escolar-no-tratamentoprevencao-.htm.

PAULILO, Maria Ângela Silveira. JEOLÁS, Leila Solberger. Jovens, drogas, risco e vulnerabilidade: aproximações teóricas. Revista Londrina, v. 3, n. 1, p.39-60, jul./dez. 2000.

PROERD. Programa Educacional de Resistência às Drogas e à Violência. Histórico do programa. Disponível em: <http://www.proerdbrasil.com.br/oproerd/oprograma.htm>. Acesso em 21 de setembro de 2014, às 08h00min.

SANCHEZ, Zila van der Meer; NAPPO, Solange Aparecida. Intervenção religiosa na recuperação de dependentes de drogas. Revista de Saúde Pública, v. 42, n. 2, p. 265-272, 2008.

SILVA, Edson Edalcio Aragão. Princípios da prevenção ao abuso de drogas. Conselho Estadual de Políticas sobre drogas do Ceará. Fortaleza, 2014. E mail: cepod@sspds.ce.gov.br.

TIBA, Içami. Juventude e Drogas: Anjos caídos - Para pais e educadores. São Paulo: Integrare, 2007.

\section{Como citar este artigo (Formato ABNT):}

GUEDES, J.D.; NÓBREGA, A.F. Efeitos do Programa Educacional de Resistência às Drogas e à Violência (PROERD) entre Estudantes do Ensino Fundamental no Cariri Cearense: Um estudo Comparativo. Id on Line Revista de Psicologia, Novembro de 2015, vol.9, n.28. p. 07- 29. ISSN 1981-1189. 